\title{
The Intersection of Oncology Prognosis and Cancer Rehabilitation
}

\author{
Sean Robinson Smith ${ }^{1}$ - Jasmine Yiqian Zheng ${ }^{1}$ \\ Published online: 1 March 2017 \\ (C) The Author(s) 2017. This article is published with open access at Springerlink.com
}

\begin{abstract}
Purpose of review This review examines the delivery of rehabilitation care to cancer patients with relation to disease prognosis. This includes the evaluation when patients are referred for rehabilitation services and the effectiveness of rehabilitation interventions across the cancer continuum.

Recent findings Although prognosticating life expectancy is difficult, referrals for rehabilitation interventions appear to be affected by physician attitudes towards patients with advanced disease, in part because of misconceptions about the nature of rehabilitation for oncology patients. Rehabilitation may also be underutilized in long-term survivors with no evidence of disease. Despite this, our review found that rehabilitation in advanced disease, end-of-life, geriatric cancer patients, and in long-term survivors can be beneficial. There is a relative dearth in studies on rehabilitation interventions specifically at the end-of-life.

Summary Cancer rehabilitation can be helpful to patients along the spectrum of cancer prognoses. Examining more accurate ways to prognosticate life expectancy, improving communication and education between oncologists and rehabilitation team members, and modifying survivorship plans to include patient education on functional changes over time may improve the delivery of rehabilitation care.
\end{abstract}

This article is part of the Topical Collection on Cancer Rehabilitation

Sean Robinson Smith

srsz@med.umich.edu

Jasmine Yiqian Zheng

jyzheng@med.umich.edu

1 Department of Physical Medicine \& Rehabilitation, University of Michigan, 325 E Eisenhower Pkwy, Ste 100, Ann Arbor, MI 48108, USA
Keywords Cancer rehabilitation · Cancer prognosis · Prognosis and supportive care $\cdot$ Prognosis and rehabilitation . Geriatric cancer rehabilitation - Cancer rehabilitation attitudes

\section{Introduction}

The dynamic and complex nature of oncology patients creates challenges in providing rehabilitation care. As patients progress through treatments and/or their disease advances, the rehabilitation target may move - a goal of independent functioning and returning to work may abruptly change to requiring assistance with activities of daily living and moving to an accessible home. These changes are even more pronounced when a patient's prognosis changes, as someone who is expected to be a long-term survivor of cancer will undoubtedly have different rehabilitation goals and expectations than someone with a life expectancy fewer than 6 months.

The evolution of symptom burden and impaired function as the disease trajectory advances is an ongoing area of study, but it is clear that the rehabilitation needs of patients change as their prognosis does and that all patients across the cancer continuum potentially have rehabilitation needs. For example, Beernaert et al. found that patients with advanced cancer report poorer function and increased fatigue and pain compared to other cancer patients after controlling for age, gender, and type of cancer [1]. Additionally, patients undergoing initial cancer treatment with curative intent also had more severe pain and worse physical function than healthy controls.

We sought to evaluate prognosis as it intersects with delivering rehabilitation and supportive care services. Using the search terms listed in Table 1, we found a variety of studies evaluating the effectiveness of rehabilitation across the spectrum of prognosis associated with cancer, though interventions were often not compared between cohorts with different 
Table 1 Search terms used for data collection for this article

"Cancer prognosis and rehabilitation"a

"Cancer survivorship and rehabilitation"

"Long-term survivors and cancer and rehabilitation"

"Cancer rehabilitation and falls"

"Geriatric and cancer rehabilitation"

"Prognosis and symptom management or rehabilitation or palliative care"

"Cancer and function and rehabilitation"

"Palliative care and rehabilitation and prognosis"

${ }^{\mathrm{a}}$ Most helpful search term

prognoses. Many variables confound the evaluation and delivery of rehabilitation services across the cancer continuum, including clinician bias with respect to prognosis, supportive care needs, difficulty predicting prognosis, and inadequate care delivery models. In this review, we will discuss these components vis-à-vis the relationship between prognosis and cancer rehabilitation, as well as current relevant studies evaluating rehabilitation across the cancer continuum.

\section{Physician Attitudes About Rehabilitation in Different Stages of Disease}

Despite efforts to improve patient access to rehabilitation and supportive services, physician bias regarding rehabilitation across the spectrum of disease may lead to unmet patient needs. Spill et al. found that only $8 \%$ of the medical oncologists - compared to $35 \%$ of physiatrists - would recommend a patient with functional goals and advanced cancer (612 months of estimated survival) be admitted to an inpatient rehabilitation unit, but $70 \%$ of the combined cohorts believed that a patient must fully understand their prognosis before entering into a comprehensive rehabilitation program [2]. It is worth pointing out that while physiatrists in general were more willing to accept a patient with advanced cancer to inpatient rehabilitation, nearly two-thirds of those surveyed did not think that a patient with 12 months or less estimated survival should undergo comprehensive rehabilitation. Another study found that palliative care physicians would like to better incorporate rehabilitation in end-of-life care, but when surveyed, they reported concerns that rehabilitation would provide false hope to patients and that a palliative care service lacks the knowledge and resources to adequately carry out high-quality rehabilitation measures [3••]. This disconnect may be due to perceptions that rehabilitation need be a lengthy process that will take up a significant proportion of the patient's remaining life expectancy. Table 2 outlines physician attitudes that may be barriers to referral to rehabilitation services in cancer patients.

In fact, cancer rehabilitation, when focusing on addressing specific impairments, may be quite efficient and is effective in reducing symptom burden [4]. This bias against rehabilitation in end-of-life scenarios, however, may create imbalanced care models and lead to patients being undertreated. For physiatrists, those who specialize in cancer rehabilitation and therefore are more comfortable managing patients with advanced cancer may be more aggressive in developing rehabilitation plans. Furthermore, it has been shown that medical oncologists who are comfortable with end-of-life care are far more likely to refer for palliative- - but not necessarily end-of-lifeservices [5].

Physician attitudes about prognosis also appear to be the most important consideration in initiating palliative systemic treatment in advanced cancer, as Buiting et al. found that nearly half of medical oncologists documented it as part of their decision making [6]. Performance status, on the other hand, was only considered in $16 \%$ of decisions to provide systemic treatment, underscoring that life expectancy is often considered to be more important than physical function when evaluating whether or not to aggressively treat patients.

In an attempt to standardize when patients are referred for rehabilitation based on prognosis, Jarlbaek et al. suggest that patients who live longer than 2 years post-cancer diagnosis may be better candidates for rehabilitation programs than hospice and end-of-life care programs. In their study of over 24,000 patients, $78 \%$ who died did so within 2 years of cancer diagnosis, and many of those that lived longer than 2 years often lived for several more years [7]. This study does not control for many factors, including cancer diagnosis, and does not look at the specific rehabilitation needs of patients before determining whether or not rehabilitation would have been warranted. For example, a patient who lives 18 months after cancer diagnosis may derive benefit from a short inpatient rehabilitation stay if functional impairment is present early on, or a patient with 3 months to live may have less pain secondary to rehabilitation interventions.

\section{Challenges in Prognosticating Life Expectancy}

It is not clear that providers can accurately predict prognosis. This is particularly worrisome if physician bias about perceived prognosis is a major factor in determining who receives rehabilitation care. A recent study found that using an assessment tool - the palliative prognostic score $(\mathrm{PaP})$ - was significantly more accurate in determining both 30- and 100-day survival when compared to using the tool combined with clinician prediction, and to clinician assessment alone [8]. Other studies have also shown objective assessment to be more accurate than clinician gestalt regarding prognosis, particularly when prognosticating 3 months or less into the future [9].

Rehabilitation may be time consuming, and oncologists may be biased against referring patients with limited life expectancies to these services. Because of this, it is important to factor in patients' goals of care; for example, some patients 
Table 2 Physician barriers to rehabilitation referrals

\begin{tabular}{ll}
\hline Study & Barrier to rehabilitation referral \\
\hline $\begin{array}{l}\text { Spill [2] } \\
\text { Runacres [3••] }\end{array}$ & $\begin{array}{l}\text { Poor use of patient time and medical resources at end-of-life, sometimes unnecessary } \\
\text { anadequate training to provide rehabilitation, do not want to give the patient false hope } \\
\text { at end }\end{array}$ \\
Virgo [74] & $\begin{array}{l}\text { Inadequate awareness and training to evaluate for rehabilitation needs, defensive medicine } \\
\text { Libert [75] }\end{array}$ \\
Inadequate training to screen for symptoms, insufficient clinic time \\
\hline
\end{tabular}

with less than 3 months to live may desire to undergo 2 weeks of inpatient rehabilitation if it reduces caregiver burden. Unfortunately, patients are generally unsure of their prognosis and tend to be more optimistic than oncologists, as demonstrated in a recent study that found $68 \%$ of the patients to be discordant with their oncologists when estimating life expectancy [10]. Another study showed that discordance also exists between physicians and surrogate decision makers of patients in $53 \%$ of the patients and that factors contributing to this difference included the need to be feel optimistic to benefit the patient, religious beliefs, and lack of physician understanding about a patients' ability to recover from physical and cognitive impairments [11].

Unrealistic expectations about prognosis have the potential to create unrealistic goals of care. This underscores the need for effective communication between patients and their oncology teams about long-term planning, including rehabilitation care. Conversely, patients often experience hope and optimism despite understanding their life expectancy. Reasons for this are multifactorial and not always well-understood by health professionals but may explain why patients seek restorative interventions such as cancer rehabilitation despite a poor prognosis [12].

\section{Delivering Rehabilitation and Supportive Care Across the Continuum}

Understanding when to refer patients for rehabilitation services presents an ongoing challenge. Numerous organizations have advocated and developed criteria for evaluation of patients for rehabilitation needs and other supportive care services without a qualifier of patient prognosis [13-15]. The message is clear: all patients should be evaluated for and provided access to rehabilitation treatment regardless of when their cancer treatment began or their estimated life expectancy.

For patients in whom the disease is presumably cured, the Commission on Cancer (COC) has attempted to improve evaluation and referrals for long-term care by mandating survivorship care plans (SCP). These serve as a way to inform patients about potential short- and long-term complications from cancer or its treatment, and explain how to obtain supportive care services [16]. Unfortunately, while SCPs increase the likelihood of patients attending follow-up visits, they do not appear to increase awareness about the late or long-term effects of cancer [17], and there is a lack of consensus on format and delivery of the plans [18].

Furthermore, SCPs provide an early opportunity to inform patients about potential rehabilitation needs, but they are not designed for patients with advanced cancer or to inform patients about functional decline as disease advances and prognosis changes. Although plans of care in advanced cancer have been proposed, there exists no standard in providing patients information about symptom management and rehabilitation need [19].

For patients with advanced cancer or higher symptom burden, the National Comprehensive Cancer Network (NCCN) has proposed criteria to determine if patients should be referred for palliative care services in order to provide symptom management. Specifically, the NCCN recommends that if patients display any one of the following six attributes, palliative care referral should be initiated: (1) uncontrolled symptoms; (2) moderate-to-severe distress; (3) serious comorbid physical or psychosocial condition; (4) advanced or progressive disease without available curative therapy; (5) patient/family concerns about decision making; (6) or patient/family request for palliative care [20]. Levy et al. found that referring to palliative care based on these criteria led to reduced symptom burden and more patient referrals [21]. Numerous studies have shown that early palliative care reduces symptom burden [22, 23], but care delivery is inadequate for reasons that include a lack of personnel and inefficient and inconsistent referral mechanisms [24]. For example, one retrospective review of 100 patients at the MD Anderson Cancer Center found that patients referred early for supportive care may be those who are younger and have obvious treatment-related side effects and that radiation oncologists were more likely to refer than medical oncologists [25]. It is important to note that these studies show that early intervention reduces symptom burden, which has not been specifically studied in the context of cancer rehabilitation.

A recent meta-analysis of outpatient palliative care referrals found inconsistent evaluation and referral mechanisms for patients across the cancer continuum. The most important criteria for referring a patient were physical symptoms $(62 \%$ of the studies in the analysis) and cancer trajectory (62\%), followed by prognosis (33\%) and performance status $(33 \%)$ 
[26••]. The analysis concluded that there was inconsistency in cutoffs of symptom assessment tools and timing for referrals and that better standardization of the process would improve identification of supportive care needs of patients.

\section{Rehabilitation in Advanced Cancer and End of Life}

As outlined above, uncertainty about the benefits and necessity of rehabilitation in cancer care largely center on patients with a poor prognosis. This may be due to multiple factors, including considerations surrounding the appropriateness of time- and resource-intensive services for patients with limited life expectancy. While palliative care and hospice at the endof-life is generally felt to be important and effective [27, 28], cancer rehabilitation is not as widely adopted nor understood in this patient population and may be underutilized [29].

Rehabilitation at the end of life may cover many facets, including outpatient, inpatient, and hospice-based interventions. Outpatient intervention has the potential to provide rapid assessment and relief of symptoms. Referral to a physiatrist to diagnose and treat neuromusculoskeletal, pain, functional, and other symptoms should be considered as a part of impairment-driven rehabilitation [4]. Many patients with advanced disease seen in a cancer rehabilitation clinic will have metastases to the bone and/or brain, and physiatrists are wellequipped to intervene in both scenarios.

Patients with bony metastases may need expert assessment of lesions to determine stability and proper management. For example, vertebral metastases often do not require surgical or radiation-based intervention, though this must be first evaluated systematically based on the location, size, and nature of each lesion [30]. Physiatrists are often key members of the multidisciplinary spine oncology team, both in providing this assessment and the subsequent treatment, including bracing, exercise, medications, and interventional pain procedures [31]. Furthermore, rehabilitation and resistance training concurrent with radiation in the presence of axial and peripheral bone metastases has been shown to improve bone density and strength without contributing to fractures [32].

Central nervous system lesions also often require physiatric evaluation and management, as primary and metastatic brain tumors can create numerous cognitive and neurologic deficits. Despite the ultimately poor prognosis of these cancers, rehabilitation intervention can improve function and quality of life, safety and independence, and reduce resource utilization by improving care coordination and preventing injury. Difficulties in accurately prognosticating survival in the presence of brain metastases has the potential to reduced appropriate rehabilitation utilization. One study of 2700 cases found that $45 \%$ of the estimations were off by 6 or more months, and $18 \%$ were off by 12 months. Performance status - which rehabilitation may improve - and age may be the biggest factors in determining prognosis in this patient population [33••].
Rehabilitation in the setting of brain metastases involves managing the effects of both the tumor(s) and the surgery and/ or radiation. Whole brain radiation, for multiple or large lesions, can cause significant long-term cognitive impairment but is becoming less common with the advent of more precise radiation-based interventions [34]. Risk factors for radiationinduced cognitive impairment include higher total and fractionated dosing, increased brain volume radiated, combined chemotherapy, age over 60 years or less than 7 years old, and premorbid vascular disease [35]. Cognitive rehabilitation may take many forms and has been shown to improve executive functioning, working memory, and other areas of cognition to varying degrees [36] despite a Cochrane review of cognitive rehabilitation in brain metastases demonstrating no strong evidence to support any one specific non-pharmacologic intervention [37]. Therefore, treatment should be supportive and multidisciplinary, tailoring to each patient's needs based on their symptoms. In addition to cognitive rehabilitation, this may include pharmacologic management by a physiatrist and interventions to boost physical activity.

Regardless of the presence of metastases, inpatient rehabilitation improves function and is safe in patients with advanced cancer. Although patients with advanced cancer may utilize inpatient rehabilitation more than those with controlled disease [38], Sliwa et al. found that patients with metastases benefitted from inpatient rehabilitation similarly to patients without metastatic or advanced disease, regardless of the presence of common inpatient rehabilitation diagnoses such as spinal cord injury (SCI), stroke, or neuromuscular disease [39.0]. Furthermore, patients with impairments such as SCI due to tumor compression have been shown to benefit from inpatient rehabilitation [40]. One study comparing 143 patients with malignant spinal cord compression found that patients with cancer-related SCI had similar length of stay, functional scores, and discharge location compared to nontraumatic SCI patients without cancer [41]. Inpatient rehabilitation has been consistently shown to improve function and help ensure a safe discharge home in many other advanced and complex cancer patient populations [42], including brain tumor [43], hematologic malignancy [44], paraneoplastic disease [45, 46], and stage II-III tumors [47]. The benefits of inpatient rehabilitation in cancer patients also appear to be independent of age [48].

In the end-of-life and hospice setting, rehabilitation interventions have been shown to improve independence, reduce anxiety and depression, and improve fatigue, among other benefits [49-52]. One randomized control trial compared hospice patients who received daily rehabilitation compared to usual care, and found that the rehabilitation group resulted in less unmet needs at the end of life in psychological, physical, activities of daily living, care and support, and pain domains. The rehabilitation intervention group also utilized fewer resources $[53 \bullet \bullet$. Furthermore, studies have shown that 
musculoskeletal pain is prevalent at the end of life [54], and the rise of ultrasound-guided procedures is allowing more rapid intervention for acute pain during hospice, opening avenues for physiatric management of end-of-life pain [55].

Finally, it is important to discuss the rehabilitation of geriatric patients with cancer. Even when the cancer is early stage, older patients are at a greater risk for morbidity and mortality, in part due to cancer treatment accelerating the aging process, and goal setting must be done in the setting of both the disease and the patient's age [56]. Nevertheless, older adults with cancer have rehabilitation and supportive care needs across the continuum and should not be overlooked despite what may seem like a poorer prognosis than younger diseasematched patients [57]. In fact, Pergolotti et al. found that there are numerous potentially modifiable functional deficits in older adults with cancer, but that even when impairments are identified, rehabilitation services are under-utilized [58]. This is a larger problem when one considers that over $60 \%$ of pain in geriatric patients at the end of life is musculoskeletal and that rehabilitation interventions are uniquely suited to address these symptoms [59].

Another important area of rehabilitation concern is fall risk in the geriatric cancer patient. Spoelstra et al. found that older cancer survivors are $16 \%$ more likely to experience a fall than their cancer-free peers $\left[60^{\bullet} \cdot\right.$, which may be due to multiple factors, including chemotherapy-induced peripheral neuropathy, deconditioning, and cognitive impairment [61]. Rehabilitation interventions to improve balance, endurance, strength, and to provide adaptive equipment and pain relief all can decrease the risk of falls in this population. Studies have shown that geriatric patient independence with ADLs is essential to quality of life and survival [62] and that rehabilitation interventions are crucial to preventing functional decline [63]. Despite this, rehabilitation needs in geriatric cancer patients may be overlooked despite their requiring and benefitting from rehabilitation services more than other patient cohorts.

\section{Rehabilitation in Long-Term Survivors and Those with a Favorable Prognosis}

Although much of the controversy about the efficacy and appropriateness of rehabilitation understandably centers on the end of life, it is important to note that patients with the opposite prognosis - those whose cancers have been cured and/or who are expected to have a normal lifespan - may have rehabilitation needs overlooked, because lifesaving treatment has completed, and it is presumed that patients will recover from deficits over time. This is not always the case, as one study found that $38.2 \%$ of the unmet needs in cancer survivors 2-, 5-, and 10-year post-treatment were physical needs [64]. The long-term negative effects of cancer and its treatment have been well documented in the literature and are at the core of the cancer rehabilitation specialty [65]. Cancer care guidelines consistently recommend long-term, longitudinal assessment of supportive care needs, including rehabilitation [13-15].

The decline in function related to cancer treatment occurs early. For example, breast cancer patients experience increased fatigue and lower physical function and activity during and after chemotherapy, neither of which improve significantly without intervention [66]. Additionally, patients selfreport a lower quality of life during the first year of being disease free compared to their perception of quality of life prior to disease onset, as well as compared to 5-years after being diagnosed with cancer [67]. This underscores the importance of early intervention and for the rest of the cancer survivor's life. Different models have been proposed for this, including the prospective surveillance model, in which providers follow patients from diagnosis, and through both oncologic treatment and rehabilitation $[68,69]$. Depending on the patient population, different approaches may be necessary, such as an interdisciplinary team that addresses the challenges faced by pediatric cancer survivors transitioning to adulthood [70].

While rehabilitation and exercise have consistently been shown to be beneficial across the cancer continuum including in long-term survivors [71, 72, 73], it is unclear which specialty and care delivery model is best equipped to meet the challenges of the growing cancer survivor population. Primary care has taken up the mantle of managing deleterious effects of cancer-the American Society of Clinical Oncology's Survivorship Symposium is a joint effort between medical oncology and primary care - despite the fact that primary care physicians and oncologists both self-report not having the proper training, nor the in-clinic time, to evaluate and treat the physical and cognitive sequelae or cancer treatment $[74,75]$. Furthermore, when rehabilitation needs are diagnosed, referrals for rehabilitation services are lacking [76-78].

Physiatrists and other rehabilitation providers are uniquely suited to manage neuromusculoskeletal and cognitive deficits in cancer survivors, and their involvement may reduce unmet rehabilitation needs in this population [16]. Improving function becomes all the more important when one considers that weight gain is a risk factor for cancer recurrence among those with no evidence of disease [79]. As the number of cancer survivors and therefore study cohorts grow, research may help determine the optimal pathway to long-term recovery; until then, it is clear that patients must take ownership of their care and empower themselves with all available resources [80].

Finally, rehabilitation has been consistently shown to help cancer survivors return to work, which is beneficial both economically and for patient well-being, as cancer survivors who have job-loss related to a health issue have lower healthrelated quality of life [81]. Fortunately, patients with support from rehabilitation physicians, and their family and friends, have not only been shown to be more likely to return to work 
but also to have a positive outlook on their employment despite a potential change in function caused by cancer $[82,83]$. In one study looking at high-intensity training in long-term cancer survivors, rehabilitation interventions made it easier to return to work [84]. A comprehensive, multidisciplinary approach may be needed to help patients with no evidence of disease return to work, particularly in patients with negative predictors of returning to work, including older age, lower income, history of chemotherapy, a job requiring heavy physical activity, and low education level [85].

\section{Conclusion}

A patient's medical prognosis has the ability to impact rehabilitation and supportive measures in many ways, including physician bias and resultant lack of proper referrals. Despite this, rehabilitation interventions appear to be generally effective in improving function and reducing symptom burden in cancer patients across the spectrum of different prognoses. Unfortunately, studies evaluating interventions at the end of life are limited, and more likely to be short series or case reports, making the literature imbalanced in favor of interventions in the earlier stages of disease [86]. This creates potential physician bias and may explain some perceptions of rehabilitation in advanced disease.

Additionally, most of the available research focuses on palliative care, which can include management of symptoms treated by rehabilitation providers, such as pain and functional impairment, but is a broad topic, and the studies are often nonspecific about what palliative care interventions are offered. Although there is overlap between cancer rehabilitation and palliative care, it is important to note that there are distinctions in the two fields, primarily that palliative care typically addresses end of life considerations in more than just cancer patients - including spiritual and social or financial concernsand cancer rehabilitation emphasizes restoring function and reducing symptom burden through identification and management of specific impairments in cancer patients [29].

It is important that rehabilitation be considered in all cancer patients who require it, regardless of prognosis. The challenge facing clinicians and researchers is developing actionable rehabilitation referral mechanisms and interventions specifically tailored to patients at different points of the disease continuum.

\section{Compliance with Ethical Standards}

Conflict of Interest Sean Smith and Jasmine Zheng declare that they have no conflict of interest.

Human and Animal Rights and Informed Consent This article does not contain any studies with human or animal subjects performed by any of the authors.
Open Access This article is distributed under the terms of the Creative Commons Attribution 4.0 International License (http:// creativecommons.org/licenses/by/4.0/), which permits unrestricted use, distribution, and reproduction in any medium, provided you give appropriate credit to the original author(s) and the source, provide a link to the Creative Commons license, and indicate if changes were made.

\section{References}

Papers of particular interest, published recently, have been highlighted as:

- Of importance

•. Of major importance

1. Beernaert K, Pardon K, Van den Block L, Devroey D, De Laat M, Geboes K, Surmont V, Deliens L, Cohen J. Palliative care needs at different phases in the illness trajectory: a survey study in patients with cancer. European journal of cancer care. 20161.

2. Spill GR, Hlubocky FJ, Daugherty CK. Oncologists' and physiatrists' attitudes regarding rehabilitation for patients with advanced cancer. PM\&R. 2012;4(2):96-108.

3.• Runacres F, Gregory H, Ugalde A. 'The horse has bolted I suspect': A qualitative study of clinicians' attitudes and perceptions regarding palliative rehabilitation. Palliat Med. 2016;26:0269216316670288. This study found that while oncologists feel that rehabilitation is important, there are misconceptions about what rehabilitation entails, and concern regarding providing adequate rehabilitation services to patients.

4. Silver JK, Baima J, Mayer RS. Impairment-driven cancer rehabilitation: an essential component of quality care and survivorship. CA Cancer J Clin. 2013;63(5):295-317.

5. Hui D, Cerana MA, Park M, Hess K, Bruera E. Impact of Oncologists' Attitudes Toward End-of-Life Care on Patients' Access to Palliative Care. The Oncologist. 2016:theoncologist2016.

6. Buiting HM, Brink M, Wijnhoven MN, Lokker ME, van der Geest LG, Terpstra WE, Sonke GS. Doctors' reports about palliative systemic treatment: a medical record study. Palliat Med. 2016;4: 0269216316661685.

7. Jarlbaek L, Christensen L, Bruera E, Gilså HD. The epidemiology of long-and short-term cancer survivors. A population-based cohort study exploring denominators for rehabilitation and palliative care programs. Acta Oncol. 2014;53(4):493-501.

8. Hui D, Park M, Liu D, Paiva CE, Suh SY, Morita T, Bruera E. Clinician prediction of survival versus the Palliative Prognostic Score: which approach is more accurate? Eur J Cancer. 2016;64: 89-95.

9. Alsirafy SA, Zaki O, Sakr AY, Farag DE, El-Sherief WA, Mohammed AA. The use of the Chuang's prognostic scale to predict the survival of metastatic colorectal cancer patients receiving palliative systemic anticancer therapy. Indian Journal of Palliative Care. 2016;22(3):312.

10. Gramling R, Fiscella K, Xing G, Hoerger M, Duberstein P, Plumb S, Mohile S, Fenton JJ, Tancredi DJ, Kravitz RL, Epstein RM. Determinants of Patient-Oncologist Prognostic Discordance in Advanced Cancer. JAMA oncology. 2016.

11. White DB, Ernecoff N, Buddadhumaruk P, Hong S, Weissfeld L, Curtis JR, Luce JM, Lo B. Prevalence of and factors related to discordance about prognosis between physicians and surrogate decision makers of critically ill patients. JAMA. 2016;315(19):208694. 
12. Nierop-van Baalen, Carine, et al. Hope dies last... A qualitative study into the meaning of hope for people with cancer in the palliative phase.European journal of cancer care (2016).

13. McCabe MS, Bhatia S, Oeffinger KC, Reaman GH, Tyne C, Wollins DS, Hudson MM. American Society of Clinical Oncology statement: achieving high-quality cancer survivorship care. J Clin Oncol. 2013;31(5):631-40.

14. Fashoyin-Aje LA, Martinez KA, Dy SM. New patient-centered care standards from the commission on cancer: opportunities and challenges. The journal of supportive oncology. 2012;10(3):10711.

15. Harris SR, Schmitz KH, Campbell KL, McNeely ML. Clinical practice guidelines for breast cancer rehabilitation. Cancer. 2012;118(S8):2312-24.

16. Smith SR, Reish AG, Andrews C. Cancer survivorship: a growing role for physiatric care. PM\&R. 2015;7(5):527-31.

17. Jabson JM. Follow-up care instructions, treatment summaries, and cancer survivors' receipt of follow-up health care and late/long term effects. Support Care Cancer. 2015;23(7):1851-6.

18. Keesing S, McNamara B, Rosenwax L. Cancer survivors' experiences of using survivorship care plans: a systematic review of qualitative studies. J Cancer Surviv. 2015;9(2):260-8.

19. Mayer DK, Green M, Check DK, Gerstel A, Chen RC, Asher G, Wheeler SB, Hanson LC, Rosenstein DL. Is there a role for survivorship care plans in advanced cancer? Support Care Cancer. 2015;23(8):2225-30.

20. Levy MH, Adolph MD, Back A, Block S, Codada SN, Dalal S, Deshields TL, Dexter E, Dy SM, Knight SJ, Misra S. Palliative care. J Natl Compr Cancer Netw. 2012;10(10):1284-309.

21. Glare P, Plakovic K, Schloms A, Egan B, Epstein AS, Kelsen D, Saltz L. Study using the NCCN guidelines for palliative care to screen patients for palliative care needs and referral to palliative care specialists. J Natl Compr Cancer Netw. 2013;11(9):1087-96.

22. Zimmermann C, Swami N, Krzyzanowska M, Hannon B, Leighl N, Oza A, Moore M, Rydall A, Rodin G, Tannock I, Donner A. Early palliative care for patients with advanced cancer: a clusterrandomised controlled trial. Lancet. 2014;383(9930):1721-30.

23. Temel JS, Greer JA, Admane S, Gallagher ER, Jackson VA, Lynch TJ, Lennes IT, Dahlin CM, Pirl WF. Longitudinal perceptions of prognosis and goals of therapy in patients with metastatic nonsmall-cell lung cancer: results of a randomized study of early palliative care. J Clin Oncol. 2011;29(17):2319-26.

24. Hui D, Bruera E. Integrating palliative care into the trajectory of cancer care. Nat Rev Clin Oncol. 2016;13(3):159-71.

25. Kwon JH, Hui D, Chisholm G, Ha C, Yennurajalingam S, Kang JH, Bruera E. Clinical characteristics of cancer patients referred early to supportive and palliative care. J Palliat Med. 2013;16(2):148-55.

26.• Hui D, Meng YC, Bruera S, Geng Y, Hutchins R, Mori M, Strasser F, Bruera E. Referral Criteria for Outpatient Palliative Cancer Care: A Systematic Review. The oncologist. 2016:theoncologist-2016. This study found that referrals for palliative care services were inconsistent, and that prognosis was only taken into consideration onethird of the time.

27. Singer AE, Goebel JR, Kim YS, Dy SM, Ahluwalia SC, Clifford M, Dzeng E, O'Hanlon CE, Motala A, Walling AM, Goldberg J. Populations and interventions for palliative and end-of-life care: a systematic review. J Palliat Med. 2016;19(9):995-1008.

28. Salins N, Patra L, Rani MU, Lohitashva SO, Rao R, Ramanjulu R, Vallath $\mathrm{N}$. Integration of early specialist palliative care in cancer care: survey of oncologists, oncology nurses, and patients. Indian Journal of Palliative Care. 2016;22(3):258.

29. Silver JK, Raj VS, Fu JB, Wisotzky EM, Smith SR, Kirch RA. Cancer rehabilitation and palliative care: critical components in the delivery of high-quality oncology services. Support Care Cancer. 2015;23(12):3633-43.
30. Fourney DR, Frangou EM, Ryken TC, DiPaola CP, Shaffrey CI, Berven SH, Bilsky MH, Harrop JS, Fehlings MG, Boriani S, Chou D. Spinal instability neoplastic score: an analysis of reliability and validity from the spine oncology study group. J Clin Oncol. 2011;29(22):3072-7.

31. Kramer S, Ruppert LM. How Rehabilitation Services Provide Benefit for Patients With Spinal Metastases. The ASCO Post. 2016.

32. Rief H, Petersen LC, Omlor G, Akbar M, Bruckner T, Rieken S, Haefner MF, Schlampp I, Förster R, Debus J, Welzel T. The effect of resistance training during radiotherapy on spinal bone metastases in cancer patients-a randomized trial. Radiother Oncol. 2014;112(1):133-9.

33.•• Venur VA, Ahluwalia MS. Prognostic scores for brain metastasis patients: use in clinical practice and trial design. Chinese clinical oncology. 2015 16;4(2). This study found that predicting survival in the presence of brain metastases is difficult, and that many predictions were off by six months or more.

34. Zhao Q, Qin Q, Sun J, Han D, Wang Z, Teng J, Li B. Brain radiotherapy plus concurrent temozolomide versus radiotherapy alone for patients with brain metastases: a meta-analysis. PLoS One. 2016;11(3):e0150419.

35. Szerlip N, Rutter C, Ram N, Yovino S, Kwok Y, Maggio W, Regine WF. Factors impacting volumetric white matter changes following whole brain radiation therapy. J Neuro-Oncol. 2011;103(1):111-9.

36. Bergo E, Lombardi G, Pambuku A, Della Puppa A, Bellu L, D'Avella D, Zagonel V. Cognitive rehabilitation in patients with Gliomas and other brain tumors: state of the art. Biomed Res Int. 2016;14:2016.

37. Day J, Zienius K, Taphoorn M, Li J, Gehring K, Grosshans D, Grant R, Brown P. Interventions for preventing and ameliorating cognitive deficits in adults treated with cranial irradiation. The Cochrane Library. 2014.

38. Ture M, Barth J, Angst F, Aeschlimann A, Schnyder U, Zerkiebel N, Perseus J, Renner C, Imesch P, Fuchs B, Huber GF. Use of inpatient rehabilitation for cancer patients in Switzerland: who undergoes cancer rehabilitation? Swiss Med Wkly. 2015;4:145.

39.• Sliwa JA, Shahpar S, Huang ME, Spill G, Semik P. Cancer rehabilitation: do functional gains relate to 60 percent rule classification or to the presence of metastasis? PM\&R. 2016;8(2):131-7. This study found that patients with functional goals benefitted from inpatient rehabilitation regardless of presence of metastases or not, or if they were receiving concurrent radiation.

40. Raj VS, Lofton L. Rehabilitation and treatment of spinal cord tumors. The journal of spinal cord medicine. 2013;36(1):11-4.

41. Fortin CD, Voth J, Jaglal SB, Craven BC. Inpatient rehabilitation outcomes in patients with malignant spinal cord compression compared to other non-traumatic spinal cord injury: a population based study. The journal of spinal cord medicine. 2015;38(6):754-64.

42. Huang ME, Sliwa JA. Inpatient rehabilitation of patients with cancer: efficacy and treatment considerations. PM\&R. 2011;3(8):74657.

43. Roberts PS, Nuño M, Sherman D, Asher A, Wertheimer J, Riggs RV, Patil CG. The impact of inpatient rehabilitation on function and survival of newly diagnosed patients with glioblastoma. PM\&R. 2014;6(6):514-21.

44. Guo Y, Shin KY, Hainley S, Bruera E, Palmer JL. Inpatient rehabilitation improved functional status in asthenic patients with solid and hematologic malignancies. American Journal of Physical Medicine \& Rehabilitation. 2011;90(4):265-71.

45. Fu JB, Raj VS, Asher A, Lee J, Guo Y, Konzen BS, Bruera E. Inpatient rehabilitation performance of patients with paraneoplastic cerebellar degeneration. Arch Phys Med Rehabil. 2014;95(12): 2496-9.

46. Smith SR, Fu JB. Paraneoplastic stiff person syndrome: Inpatient rehabilitation outcomes of a rare disease from two cancer rehabilitation programmes. Journal of rehabilitation medicine. 2016. 
47. Lamprecht J, Thyrolf A, Mau W. Health-related quality of life in rehabilitants with different cancer entities. European Journal of Cancer Care. 2016.

48. Hunter EG, Baltisberger J. Functional outcomes by age for inpatient cancer rehabilitation a retrospective chart review. J Appl Gerontol. 2013;32(4):443-56.

49. Lee WT, Chan HF, Wong E. Improvement of feeding independence in end-stage cancer patients under palliative care - a prospective, uncontrolled study. Support Care Cancer. 2005;13(12):1051-6.

50. Albrecht TA, Taylor AG. Physical activity in patients with advanced-stage cancer: a systematic review of the literature. Clin J Oncol Nurs. 2012;16(3):293-300.

51. López-Sendín N, Alburquerque-Sendín F, Cleland JA, Fernándezde-las-Peñas C. Effects of physical therapy on pain and mood in patients with terminal cancer: a pilot randomized clinical trial. The Journal of Alternative and Complementary Medicine. 2012;18(5): 480-6.

52. Barawid E, Covarrubias N, Tribuzio B, Liao S. The benefits of rehabilitation for palliative care patients. American Journal of Hospice and Palliative Medicine. 2015;32(1):34-43.

53.• Jones L, FitzGerald G, Leurent B, Round J, Eades J, Davis S, Gishen F, Holman A, Hopkins K, Tookman A. Rehabilitation in advanced, progressive, recurrent cancer: a randomized controlled trial. J Pain Symptom Manag. 2013;46(3):315-25. This randomized controlled trial found that hospice patients receiving daily multidisciplinary rehabilitation had less unmet needs at the end of life and utilized fewer resources than those receiving usual care.

54. Lillie AK, Read S, Mallen C, Croft P, McBeth J. Musculoskeletal pain in older adults at the end-of-life: a systematic search and critical review of the literature with priorities for future research. BMC palliative care. 2013;12(1):1.

55. Chernack B, Knowlton SE, Kohler MJ. The use of ultrasound in palliative care and hospice. American Journal of Hospice and Palliative Medicine. 2016;11:1049909115625960.

56. Winters-Stone KM, Bennett J, Mick D. Preventing frailty in older cancer survivors. Topics in Geriatric Rehabilitation. 2015;31(4): $241-5$.

57. Koll T, Pergolotti M, Holmes HM, Pieters HC, van Londen GJ, Marcum ZA, MacKenzie AR, Steer CB. Supportive care in older adults with cancer: across the continuum. Curr Oncol Rep. 2016;18(8):1.

58. Pergolotti M, Deal AM, Lavery J, Reeve BB, Muss HB. The prevalence of potentially modifiable functional deficits and the subsequent use of occupational and physical therapy by older adults with cancer. Journal of geriatric oncology. 2015;6(3): 194-201.

59. Smith AK, Cenzer IS, Knight SJ, Puntillo KA, Widera E, Williams BA, Boscardin WJ, Covinsky KE. The epidemiology of pain during the last 2 years of life. Ann Intern Med. 2010;153(9):563-9.

60.• Spoelstra SL, Given BA, Schutte DL, Sikorskii A, You M, Given CW. Do older adults with cancer fall more often? A comparative analysis of falls in those with and without cancer. InOncology nursing forum 2013 Mar 1 (Vol. 40, No. 2). This study found that older adults with cancer are more likely to fall compared to peers without cancer

61. Hile ES. Imbalance and falls in older cancer survivors: an evidenceinformed model for clinical assessment. Topics in Geriatric Rehabilitation. 2015;31(4):E1-9.

62. Hoppe S, Rainfray M, Fonck M, Hoppenreys L, Blanc JF, Ceccaldi J, Mertens C, Blanc-Bisson C, Imbert Y, Cany L, Vogt L. Functional decline in older patients with cancer receiving first-line chemotherapy. J Clin Oncol. 2013;31(31): 3877-82.
63. Pergolotti M, Williams GR, Campbell C, Munoz LA, Muss HB. Occupational therapy for adults with cancer: why it matters. Oncologist. 2016;21(3):314-9.

64. Burg MA, Adorno G, Lopez ED, Loerzel V, Stein K, Wallace C, Sharma DKB. Current unmet needs of cancer survivors: analysis of open-ended responses to the American Cancer Society Study of Cancer Survivors II. Cancer. 2015;121(4):623-30.

65. Stubblefield MD. Rehabilitation of the cancer patient. Devita, VT, Lawrence TS, Rosenberg Sa, editors. Devita, Hellman, \& Rosenberg's cancer: principles \& practice of oncology, 10th ed. Lippincott Williams \& Wilkins. 2014.

66. Broderick JM, Hussey J, Kennedy MJ, O’Donnell DM. Testing the 'teachable moment'premise: does physical activity increase in the early survivorship phase? Support Care Cancer. 2014;22(4):98997.

67. Hwang EJ, Lokietz NC, Lozano RL, Parke MA. Functional deficits and quality of life among cancer survivors: implications for occupational therapy in cancer survivorship care. Am J Occup Ther. 2015;69(6):6906290010p1-9.

68. Stubblefield MD, McNeely ML, Alfano CM, Mayer DK. A prospective surveillance model for physical rehabilitation of women with breast cancer. Cancer. 2012;118(S8):2250-60.

69. Stout NL, Binkley JM, Schmitz KH, Andrews K, Hayes SC, Campbell KL, McNeely ML, Soballe PW, Berger AM, Cheville AL, Fabian C. A prospective surveillance model for rehabilitation for women with breast cancer. Cancer. 2012;118(S8): 2191-200.

70. Gupta AA, Papadakos JK, Jones JM, Amin L, Chang EK, Korenblum C, Mina DS, McCabe L, Mitchell L, Giuliani ME. Reimagining care for adolescent and young adult cancer programs: Moving with the times. Cancer. 2016.

71. Speck RM, Courneya KS, Mâsse LC, Duval S, Schmitz KH. An update of controlled physical activity trials in cancer survivors: a systematic review and meta-analysis. J Cancer Surviv. 2010;4(2): $87-100$.

72. Knols R, Aaronson NK, Uebelhart D, Fransen J, Aufdemkampe G. Physical exercise in cancer patients during and after medical treatment: a systematic review of randomized and controlled clinical trials. J Clin Oncol. 2005;23(16):3830-42.

73. Palmer PB, Wallace K, Clay D, Gill C, Moore K. The efficacy of participation in a survivorship program on functional abilities and quality of life in cancer survivors: a descriptive, retrospective study. Rehabilitation Oncology. 2015;33(1):32-40.

74. Virgo KS, Lerro CC, Klabunde CN, Earle C, Ganz PA. Barriers to breast and colorectal cancer survivorship care: perceptions of primary care physicians and medical oncologists in the United States. J Clin Oncol. 2013;JCO-2012

75. Libert Y, Merckaert I, Slachmuylder JL, Razavi D. The ability of informal primary caregivers to accurately report cancer patients' difficulties. Psycho-Oncology. 2013;22(12):2840-7.

76. Cheville AL, Beck LA, Petersen TL, Marks RS, Gamble GL. The detection and treatment of cancer-related functional problems in an outpatient setting. Support Care Cancer. 2009;17(1):61-7.

77. Pergolotti M, Cutchin MP, Weinberger M, Meyer AM. Occupational therapy use by older adults with cancer. Am J Occup Ther. 2014;68(5):597-607.

78. Thorsen L, Gjerset GM, Loge JH, Kiserud CE, Skovlund E, Fløtten T, Fosså SD. Cancer patients' needs for rehabilitation services. Acta Oncol. 2011;50(2):212-22.

79. Ganz PA. Monitoring the physical health of cancer survivors: a survivorship-focused medical history. J Clin Oncol. 2006;24(32): 5105-11.

80. Loh SY, Musa AN. Methods to improve rehabilitation of patients following breast cancer surgery: a review of systematic reviews. Breast Cancer: Targets and Therapy. 2015;7:81. 
81. Lee SY, Kim SJ, Shin J, Han KT, Park EC. The impact of job status on quality of life: general population versus long-term cancer survivors. Psycho-Oncology. 2015;24(11):1552-9.

82. Duijts SF, van Egmond MP, Gits M, van der Beek AJ, Bleiker EM. Cancer survivors' perspectives and experiences regarding behavioral determinants of return to work and continuation of work. Disabil Rehabil. 2016;18:1-9.

83. Fu JB, Osborn MP, Silver JK, Konzen BS, Ngo-Huang A, Yadav R, Bruera E. Evaluating Disability Insurance Assistance as a Specific Intervention by Physiatrists at a Cancer Center. American Journal of Physical Medicine \& Rehabilitation. 2016.
84. Thijs KM, de Boer AG, Vreugdenhil G, van de Wouw AJ, Houterman S, Schep G. Rehabilitation using high-intensity physical training and long-term return-to-work in cancer survivors. J Occup Rehabil. 2012;22(2):220-9.

85. Muijen P, Weevers NL, Snels IA, Duijts SF, Bruinvels DJ, Schellart AJ, Beek AJ. Predictors of return to work and employment in cancer survivors: a systematic review. European journal of cancer care. 2013;22(2):144-60.

86. Tayjasanant S, Bruera E, Hui D. How far along the disease trajectory? An examination of the time-related patient characteristics in the palliative oncology literature. Support Care Cancer. 2016;29:1-8. 